\title{
Free recall in children as a function of list composition and sorting technique
}

\author{
ROBERT COHEN, MARILYN BOBO, and KIM ANN SENFT \\ Miami University, Oxford, Ohio 45056
}

\begin{abstract}
Kindergarten children and sixth-graders sorted pictures in one of two ways: either into the pockets of a shirt worn during the experimental session (pocket condition), or onto small boards placed before them (board condition). Each subject was given both a clusterable and a nonclusterable list of items to sort and free recall. Subjects in the sorting conditions recalled more items and clustered their recall to a significantly greater extent than a control group not allowed to sort the items prior to recall. In addition, sixth-graders demonstrated equivalent clustering of recall in the two sorting conditions, whereas kindergarten children clustered recall significantly more in the more personalized pocket condition than the more traditional board condition. Results are discussed in terms of Flavell's production deficiency hypothesis, and in terms of two facilitating functions attributed to the sorting manipulation.
\end{abstract}

Based on numerous studies using free recall of categorically related material with children, Flavell (1970) and his associates have proposed that the consistently lower recall and clustering by young children reflect a general absence of organizational activity. Rather than being cognitively unable to engage in organizational strategies, the child displays a production deficiency, i.e., he does not spontaneously seek out and use organizational cues. Support for this position comes from studies in which young children have been induced, by various experimental manipulations, to utilize appropriate organizational strategies (see Jablonski, 1974).

One such experimental manipulation is sortinghaving the child overtly manipulate and categorize the stimulus items prior to recall. Sorting has been shown to be an effective technique for facilitating the amount of both recall and clustering by young children (Lange \& Hultsch, 1970; Lange \& Jackson, 1974; Liberty \& Ornstein, 1973; Mandler \& Stevens, 1967). Sorting, therefore, serves to enhance both the recognition and the use of the experimenter-determined organization within the to-be-remembered material.

Sorting has also been shown to serve a second facilitating function in a free-recall task. Geis and Lange (Note 1) concluded that sorting can serve as a means by which the subject can produce personalized associations and cues as retrieval aids. First-, third-, and fifth-graders were equally successful in retrieving items sorted with appropriate retrieval cues, but fifth-graders were more successful than the younger

Appreciation is extended to John C. Jahnke, Robert Bornstein, and Lillian Hay for their critical comments on various drafts of this manuscript. Also the authors wish to thank the principal of Kramer Elementary School in Oxford, Ohio, Mr. Carl Garnett, for his invaluable aid with this project. John C. Jahnke sponsors this paper and takes full editorial responsibility for its content. Requests for reprints should be addressed to the first author, Department of Psychology, Miami University, Oxford, Ohio 45056. children in recalling those items placed with inappropriate, or unrelated cues. These experimenters propose that the intent to remember may not be as important a determiner of the amount of recall as the manner in which the child interacts with the to-be-remembered material. This would suggest that allowing subjects to manipulate the material, i.e., sort the items, in various ways might differentially affect the recall and clustering performances of differentaged subjects. The present study was designed to test this possibility with kindergarten and sixth-grade children, using two sorting techniques and two recall lists of different compositions.

\section{METHOD}

\section{Design}

A 2 by 3 by 2 experimental design was employed. The factors were grade level (kindergarten and sixth grade), sorting condition (pocket, board, and control) and list composition (clusterable and nonclusterable). Grade level and sorting condition were between-subject factors, while list composition was a within-subjects factor; thus each subject received one sorting condition for both clusterable and nonclusterable lists of items.

\section{Subjects}

Twenty-four kindergarten children and 24 sixth graders served as subjects. Equal numbers of males and females in each grade were randomly assigned to each of the three sorting conditions.

\section{Materials \\ Outline pictures copied from the Peabody Picture Vocabulary Test and mounted on $7.5 \times 12.5 \mathrm{~cm}$ white index cards were used as stimulus items. The 16 stimulus items composing the clusterable list were from four categories: animals-dog, cow, fish, chicken; furniture-chair, lamp, bed, desk; clothes-shirt, hat, shoe, belt; vehicles-train, car, bus, bicycle. The 16 nonclusterable items were: book, box, candle, cat, cup, doctor, boat, drum, ear, feather,} gun, pie, shovel, sock, tent, and umbrella.

\footnotetext{
Procedure

Subjects were tested individually by one of two female experimenters. In all conditions, the 16 stimuli were randomly placed face up into a 4 by 4 array on a $71 \times 56 \mathrm{~cm}$ piece of cardboard. The child pointed to and named each picture in turn,
} 
Table 1

Mean Number of Items Recalled as a Function of Grade, List Composition, and Sorting Condition

\begin{tabular}{lccc}
\hline & \multicolumn{3}{c}{ Sorting Condition } \\
\cline { 2 - 4 } List Composition & Pocket & Board & Control \\
\hline & \multicolumn{3}{c}{ Kindergarten } \\
Clusterable & 9.38 & 10.63 & 7.50 \\
Nonclusterable & 7.25 & 7.63 & 6.50 \\
& & Sixth Grade \\
Clusterable & 13.38 & 14.00 & 11.00 \\
Nonclusterable & 14.00 & 12.00 & 10.25 \\
\hline
\end{tabular}

performed this task twice, and was reminded each time that he would be asked to recall as many items as he could.

Subjects in the pocket condition were asked to "put the pictures which go together" into four $10 \times 16 \mathrm{~cm}$ pockets on the front of a shirt they had put on at the start of the session. Subjects in the board condition sorted the items onto four $10 \times 16 \mathrm{~cm}$ pieces of cardboard placed before them. To equate the exposure time of the items across groups, the control group subjects pointed to and named the stimulus items for a third time.

Subjects were then asked for free recall of the items. Following this recall, the subject was given the second list for recall, using the same procedure as he received on the first list. Half of the subjects in each condition received the clusterable list of items first; half received the list of nonclusterable items first.

\section{RESULTS}

In each of the following analyses of the number recalled and the clustering of recall, possible effects related to the sex of subject were considered. Since this variable produced no statistically significant results, it is omitted from further discussion. Newman-Keuls analyses $(p<.05)$ were used to clarify group differences where appropriate.

The mean number of items recalled by subjects is displayed in Table 1. The analysis of variance performed on these data revealed that sixth-graders recalled significantly more items than kindergartners $[F(1,36)=86.37, \mathrm{p}<.001]$, and subjects in both grades recalled significantly more items from the clusterable than from the nonclusterable list $[F(1,36)=7.17, p<.025]$. Further, subjects in the two sorting conditions recalled equivalent numbers of items, and subjects in both sorting conditions recalled significantly more items than subjects in the control condition $[\mathrm{F}(2,36)=10.27, \mathrm{p}<.001]$.

The measure of clustering of recall was applied to the data both in terms of the subject-generated categories in the two sorting conditions and in terms of the experimenter-generated categories available in the clusterable list. Frankel and Cole's (1971) Z-score clustering measure was used in both clustering analyses.

The mean Z-clustering scores using the subject-generated categories revealed significant clustering scores for all groups, with the exception of kindergarten children in the board condition on the nonclusterable list. Whereas each of the two sorting techniques promoted organization of recall for sixth-graders, only the pocket condition facilitated this activity for kindergartners with the nonclusterable list.

An anlysis of variance on the $\mathrm{Z}$ scores from the subject-generated categories revealed that sixthgraders clustered recall to a significantly greater extent than did kindergartners $[F(1,24)=22.58$, $\mathrm{p}<.001]$. Further, greater clustering of recall occurred on the clusterable than on the nonclusterable list for all subjects $[F(1,24)=49.95$, $\mathrm{p}<.001]$.

The mean Z-clustering scores using the experimenter-generated categories revealed significant clustering scores for all groups with the exception of kindergartners in the control condition. Thus, sixth-graders discovered and used the available organization in all conditions, while kindergartners did not apply this strategy when they were not allowed to manipulate the items.

An analysis of variance on the $\mathrm{Z}$ scores from the experimenter-generated categories showed that sixth-graders employed these categories more than kindergartners $[F(1,36)=23.80, p<.001]$, and greater clustering occurred in the pocket and board than in the control condition $[\mathrm{F}(2,36)=21.47$, $\mathrm{p}<.001]$. While sixth-graders in the pocket and board conditions produced equivalent amounts of clustering with these categories, kindergartners in the pocket condition clustered recall to a significantly greater extent than in the board condition $[F(2,36)=3.72, p<.05]$. The mean Z-clustering scores using both subject-generated and experimenter-generated categories may be found in Table 2.

\section{DISCUSSION}

The data from the clusterable list using experimenter-generated categories support Flavell's production deficiency hypothesis. Kindergartners not allowed to sort the stimuli did not use the available categories to a significant extent during recall, while sixth-graders in the same condition did utilize this organization.

Table 2

Mean Z-Clustering Scores as a Function of Grade, List Composition, Sorting Condition, and Categories Used

\begin{tabular}{|c|c|c|c|c|c|}
\hline \multirow{3}{*}{$\begin{array}{c}\text { List } \\
\text { Composition }\end{array}$} & \multicolumn{2}{|c|}{$\begin{array}{l}\text { Subject- } \\
\text { Generated } \\
\text { Categories }\end{array}$} & \multicolumn{3}{|c|}{$\begin{array}{l}\text { Experimenter- } \\
\text { Generated } \\
\text { Categories }\end{array}$} \\
\hline & \multicolumn{5}{|c|}{ Sorting Condition } \\
\hline & Pocket & Board & Pocket & Board & Control \\
\hline & & & ndergar & & \\
\hline \multirow{3}{*}{$\begin{array}{l}\text { Clusterable } \\
\text { Nonclusterable }\end{array}$} & 2.75 & 1.93 & 2.58 & 1.34 & .13 \\
\hline & .89 & 44 & & & \\
\hline & \multicolumn{5}{|c|}{ Sixth Grade } \\
\hline Clusterable & 4.61 & 4.85 & 4.56 & 4.76 & .79 \\
\hline Nonclusterable & 1.47 & 1.72 & & & \\
\hline
\end{tabular}

Note $-p<.05$ for a mean $Z$ score $>.69$. 
One of the functions of the sorting manipulation mentioned in the Introduction, facilitation of the discovery of available categories, is thus demonstrated in the present research.

The indices of clustering of recall from the clusterable list using the subject-generated and experimenter-generated categories were quite similar. The slightly higher clustering using the subject-generated categories suggests the occurrence of a small degree of idiosyncratic sorting. When these associations were not included in the analysis, i.e., when only categorical membership as defined by the experimenter was considered, there was a significant Grade by Sorting Technique interaction. This implies that the different sorting tasks had differential effects at the different grade levels in facilitating the recognition of the available organization. Kindergartners were aided more by the more personalized pocket-sorting task than by the more traditional board-sorting task.

The second postulated function of sorting, the promotion of personalized associations as cues for retrieval, also appears in the data, again showing different effects depending on the age of the child and the specific sorting task engaged in. With the nonclusterable list, sixth-graders significantly used their personalized associations for recall regardless of the sorting task. Kindergarten children, however, significantly used their personalized categories only in the pocket condition, and not in the board condition. It would appear to be the case, therefore, that the personalized pocket-sorting condition, relative to a sorting task which is less personalized and more external to the young child, not only facilitates the recognition of available categories, but also promotes the use of individualized sorting categories when no categories exist in the list.

\section{REFERENCE NOTE}

1. Geis, M. F., \& Lange, G. Plantul storage for planful retrieval: $A$ developmental study of cue utilization in school-aged children. Paper presented at biennial meeting of the Society for Research in Child Development. Denver, 1975.

\section{REFERENCES}

Flavell, J. H. Developmental studies of mediated memory. In H. W. Reese \& L. P. Lipsitt (Eds.), Advances in child development and behavior (Vol. 5). New York: 1970.

Frankel, F.. \& Cole, M. Measures of category clustering in free recall. Psychological Bulletin, 1971, 76, 39-44.

JABLONSKI. E. M. Free recall in children. Psychological Bulletin. 1974, 81, 522-539.

LANGE, G., \& Hultsch, D. F. The development of free classification and free recall in children. Developmental Psychology, 1970. 3. 408.

LANGE, G., \& JACKson, P. Personal organization in children's free recall. Child Development, 1974, 45, 1060-1067.

Liberty, C.. \& Ornstein, P. A. Age differences in organization and recall: The effects of training in categorization. Journal of Experimental Child Psychology, 1973, 15, 169-186.

Mandler, G., \& Stevens, D. The development of free and constrained conceptualization and subsequent verbal memory. Journal of Experimental Child Psychology, 1967, 5, 87-93.

(Received for publication December 8, 1975.) 